\title{
Anti-TIM-3 Monoclonal Antibody MBG453
}

National Cancer Institute

\section{Source}

National Cancer Institute. Anti-TIM-3 Monoclonal Antibody MBG453. NCI Thesaurus.

Code C124850.

An inhibitor of the inhibitory T-cell receptor T-cell immunoglobulin and mucin domaincontaining protein 3 (TIM-3; hepatitis A virus cellular receptor 2; HAVCR2), with potential immune checkpoint inhibitory and antineoplastic activities. Upon administration, the antiTIM-3 checkpoint inhibitor MBG453 binds to TIM-3 expressed on certain immune cells, including tumor infiltrating lymphocytes (TILs). This abrogates T-cell inhibition, activates antigen-specific T-lymphocytes and enhances cytotoxic T-cell-mediated tumor cell lysis resulting in a reduction in tumor growth. TIM-3, a transmembrane protein expressed on certain T-cells, is associated with tumor-mediated immune suppression. 